\title{
Species in the Age of Discordance
}

\author{
Matthew H. Haber*
}

\begin{abstract}
Biological lineages move through time, space, and each other. As they do, they diversify, diverge, and grade away from and into one another. One result of this is genealogical discordance; i.e., the lineages of a biological entity may have different histories. We see this on numerous levels, from microbial networks, to holobionts, to population-level lineages. This paper considers how genealogical discordance impacts our study of species. More specifically, I consider this in the context of three framing questions: (1) How, if at all, does genealogical discordance challenge, modify, or revise how we conceive of species? (2) How has growing appreciation of genealogical discordance impacted scientific practice? Of systematics in particular? (3) How do lineages at different levels diverge and diversify? All told, genealogical discordance enriches and complicates our taxonomic ontology, as well as the practice of reconstructing phylogenies. This presents both challenges and opportunities for the study of divergence and diversification.
\end{abstract}

\section{Keywords}

species $\bullet$ discordance $\bullet$ phylogenetic inference $\bullet$ diversification $\bullet$ divergence $\bullet$ complexity

Part of the special issue Species in the Age of Discordance, guest-edited by Matthew H. Haber and Daniel J. Molter.

\section{Introduction}

When I was a graduate student, the entomologist Phil Ward posed the following question in a seminar on species and phylogenetics: "Are the branches of phylogenetic trees too thin?" This question struck me then, and it has continued to resonate as I think about contemporary phylogenetics. Ward was pressing us to think about what, if anything, was lost in the way we idealize phylogenetic relationships and ignore the internal structure of those lineages. Though the term 'genealogical discordance' had not quite yet become common parlance, this was precisely what the examples Ward was using to prompt discussion were displaying. As a philosopher of science in a graduate biology seminar, I was well primed to pick up on this interrogation of the intersection of theory, method, concept, and practice.

*Department of Philosophy, School of Biology, and Center for Quantitative Biology, University of Utah, USA, matt.haber@utah.edu

Received 1 February 2019; Revised 10 April 2019; Accepted 15 April 2019 doi:10.3998/ptpbio.16039257.0011.021

๑ OPEN ACCESS - PTPBIO.ORG 
Ward posed his question soon after microbiologists were recognizing the breadth and scope of genealogical discordance in microbial networks. This was presented, by some, as a serious challenge to the central commitments of phylogenetics (e.g., Doolittle 1999; Martin 1999), though this struck me as a bit odd. After all, it was precisely from the phylogeneticists that I was learning about discordance. It was still somewhat early days, but even then it seemed apparent that phylogeneticists could see discordance as providing both opportunities and challenges e.g., Avise and Wollenberg 1997; Maddison 1997; Nichols 2001. 1 .

This paper is an attempt to articulate some of those opportunities and challenges by laying out how genealogical discordance impacts three categories of research problems in systematics. Those include (1) how discordance challenges, modifies, or revises how we ought to think about species; (2) how genealogical discordance has impacted scientific practice in systematics; and (3) what discordance reveals about how lineages diverge and diversify. My goal is not to provide comprehensive answers to those problems here, but to present them as important and fruitful framing questions in (the philosophy of) phylogenetics.

To accomplish this task, I start by offering a very brief introduction on genealogical discordance. I then use the three framing questions above to explore how this complicates and enriches our study of species and evolution in the context of phylogenetic systematics. This is helped along by discussion of examples that highlight these new challenges and opportunities. Most exciting, to me, and also most speculative, is the potential that these challenges have to connect research across biological disciplines, offering the opportunity for integrated approaches to studying divergence and diversification.

This is a programmatic paper. It is a moment to pause and evaluate the impact of recent empirical and theoretical advances in biology on phylogenetics (and systematics more generally). This has become all the more urgent as we have determined that the breadth and scope of discordance described by microbialists may be far more common beyond the microbial world than many anticipated. That's just to say that Phil Ward was exactly right. The branches on phylogenetic trees are too thin, or, at least, we need to recognize when a deep dive into those branches, and an examination of their internal structure, will bear important consequences for how we pursue phylogenetics. 1

\section{Genealogical Discordance}

Genealogical discordance, roughly, is when the lineages of a biological entity fail to align topographically, i.e., they display different phylogenetic histories. This is perhaps easiest to see in cases when there are conflicts between gene trees and species trees (see figure 11), though discordance may be exhibited within as much as between levels of lineage. Before detailing some of the specific modes of genealogical discordance, let's step back to take a bit more of a speculative and broad view on genealogical discordance.

More generally, genealogical discordance may be understood as a feature of the hierarchical structure of lineages. This hierarchy is the result of evolution, and we can ask why it evolved the way it did (rather than a different way), or why a hierarchy evolved at all (McShea 2001; Haber 2012). The modes and kinds of genealogical discordance can be viewed as features of

1. It's entirely possible this was simply a reflection of the phylogeneticists I was reading and learning from, than of the field as a whole. That said, it is also worth noting that Hennig (1966) noticed something similar, and his notion of the semaphorant and tokogeny may be worth revisiting in this context.

2. This is reminiscent of O'Hara's (1993) observation about "systematic generalization." His observation was on how the level of resolution we select for our phylogenetic trees reflects the pragmatic (research) purpose at hand. The "systematic generalization" choice presented by genealogical discordance is a related but adjacent problem. 


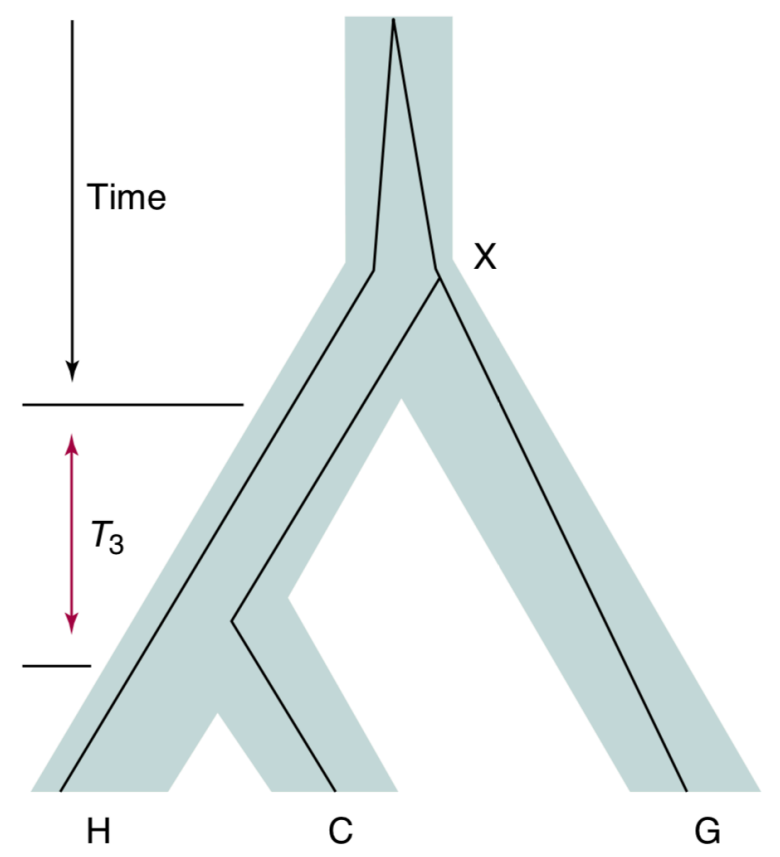

Figure 1: Nichols (2001) provides a good entry point into genealogical discordance. This figure displays how three species might share a gene whose lineage displays a branching order or phylogenetic history that differs (i.e., is 'discordant') from the branching pattern of the three containing species (Nichols 2001, 359 , box 1 , figure II). The thick gray bars represent the branching patterns of three species, $\mathrm{H}, \mathrm{C}$, and G, and the thin black line represents the branching pattern of a single gene found in all three of these species. Lines/bars come together at nodes or branching points, representing common ancestry. Here, the species and gene trees indicate conflicting patterns of genealogy. This conflict between branching patterns is an example of gene tree/species tree discordance. There are many mechanisms that can generate this sort of pattern (see text). Reprinted from Nichols (2001) with permission from Elsevier.

the hierarchy that did evolve, and we can examine both how those helped contribute to the evolution of that hierarchy, and how they may be viewed as evolved characters of that hierarchy.

One way to consider the biological hierarchy of lineages is to adopt a recursive account of the part/whole relations that evolved. That is, to treat biological individuals as "lineage generating entities that are both constituted by and constitutive of other biological individuals" (Haber 2016, 921). 3 That is just to say that if we treat lineages as biological individuals (which I do), then we need to consider (1) how they relate to other lineages as parts of more inclusive individuals; and (2) how they are, in turn, themselves constituted by lineage-generating parts (and how those parts relate to each other as parts of that individual).

When a temporal (or diachronic) perspective is applied to this recursive account of lineages, it will be an empirical question how 'tightly' constitutive lineages track each other as parts of the same persistent lineage over generational time, and we should expect variation in how tightly policed that recurrence of concordance will be. Indeed, this feature of lineages may vary, and, presumably, is sensitive to evolutionary and other biological pressures. For example, biological entities are more or less tolerant of lateral gene transfer, or of hybridization, and mechanisms have evolved to either promote or guard against these processes (Moxon et al. 1994; Howard et

3. As Haber (2016) observes, the recursive account may also require an articulation of minimal and maximal individuality, or at least the adoption of a strategy that explains why no such accounts are required (e.g., pragmatists may argue that these accounts are only needed so long as they provide some utility). 
al. 1998; Vollmer and Palumbi 2002; Bershtein et al. 2015; Harrison et al. 2015; Jablonski 2017a, 2017b). The upshot is a variation in how tightly 'boundaries' of different lineages are policed. Some lineages have evolved the capacity to gain or lose parts more or less easily, which can be expressed and measured in terms of how closely constituent lineages track each other. Moreover, diachronic individuality itself (or, at least, biological part/whole relations) may be conceived of by degree, in terms of how tightly lineages concordantly recur-be it over ontogenetic (Pradeu 2012) or evolutionary (Haber 2016) time, or the intersection of those (Doolittle and Booth 2017).

Let's return to a more concrete discussion about genealogical discordance. There are a number of biological mechanisms or processes that can generate genealogical discordance, corresponding to different modes of lineage generation and persistence. . $^{-1}$

Figure 2 displays four modes of genealogical discordance: horizontal (or lateral) gene transfer (HGT or LGT); gene duplication and loss; hybridization; and recombination. In addition to these, genealogical discordance may be the product of incomplete lineage sorting (ILS; see figure 3) (Degnan and Rosenberg 2006; Avise and Robinson 2008); symbiosis; and pseudo-vertical transmission (Wilkinson 1997; Molter, forthcoming).
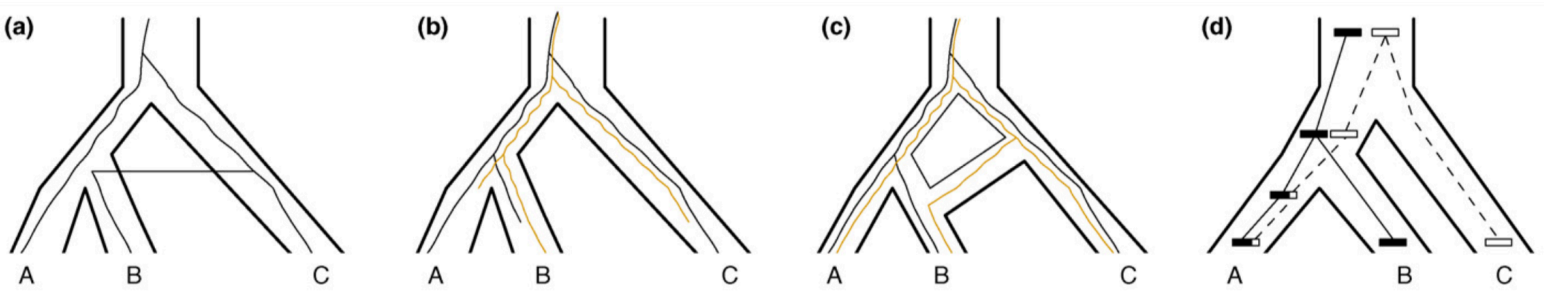

Figure 2: Genealogical discordance may be the result of different biological processes and mechanisms, including (a) Horizontal Gene Transfer (HGT); (b) gene duplication and loss; (c) hybridization; and (d) recombination (Degnan and Rosenberg 2009, 334, figure 2a-d, reprinted with permission from Elsevier).

Philosophers have recently (and fruitfully!) turned their attention to HGT, especially in the context of microbiology, the concept of microbial species, and the Tree of Life (e.g., Franklin 2007; O’Malley and Dupré 2007; O’Malley, Martin, and Dupré 2010; Bouchard 2010; Ereshefsky 2010; Franklin-Hall 2010; Velasco 2010; O’Malley 2014). Other modes of genealogical discordance are beginning to draw more attention from philosophers as well, at least in the context of how they impact the systematic study of species, be it in terms of phylogenetic inference or the ontology of taxa (Conix 2018).

Additional mechanisms and processes may also result in genealogical discordance, though less work has been done on these in the specific context presented here (and, in some cases, whether they ought to be treated as modes of inheritance is more controversial). That includes the impact of epigenetic or environmental (niche) inheritance across generations (Jablonka and Lamb 2014; K. Laland et al. 2014; K. N. Laland et al. 2015; though see Wray et al. 2014); transposable genomic elements (Brunet and Doolittle 2015; Linquist et al. 2015); host-parasite evolution (Johnson et al. 2003); and preservation, conservation, and recombination of develop-

4. Degnan and Rosenberg (2009) provide a helpful review of genealogical discordance; see Hudson (1983), Tajima (1983), Takahata and Nei (1985), Neigel and Avise (1986), Takahata (1989), Page (1993), and Page and Charleston (1997) for a sampling of foundational papers.

5. These modes need not operate in isolation or exclusively of each other. Ring species, for example, may generate downstream genealogical discordance through some combination of hybridization and incomplete lineage sorting, among other modes (Kuchta and Wake 2016).

๑ OPEN ACCESS - PTPBIO.ORG 


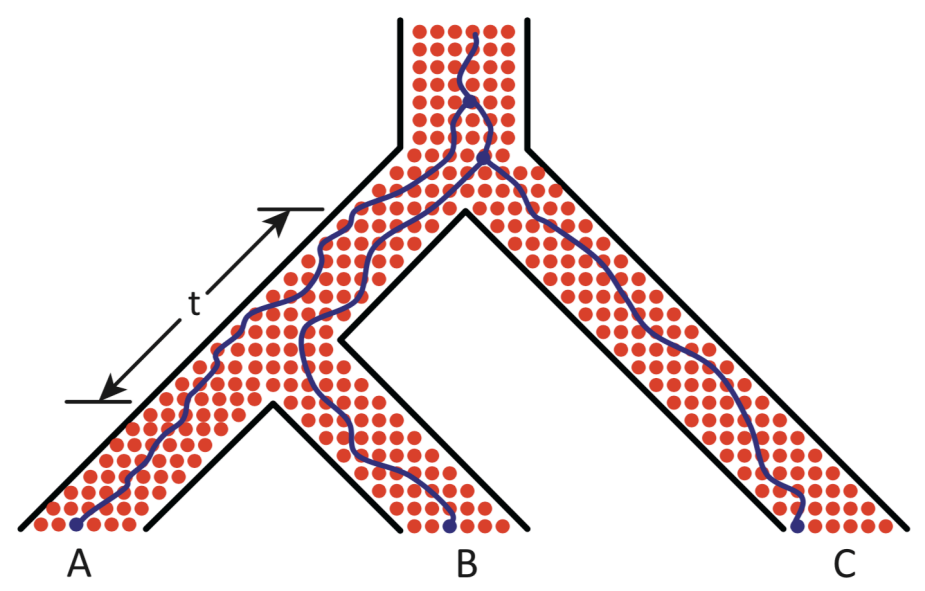

Figure 3: Incomplete lineage sorting (ILS). One way to think about ILS is as a lag time between organismal and gene level sorting after divergence, though it could, in principle, be found between any two levels of hierarchy that stand in a part/whole relation. The probability of ILS is related to population size and branch lengths, which may be expressed in terms of coalescence (Nakhleh 2013, 721, figure 3, reprinted with permission from Elsevier).

mental modules, e.g., loss/gain or activation/deactivation of gene regulatory networks (Bolker 2000; Huneman 2013; Lacquaniti et al. 2013; Hejnol and Lowe 2015).

It is important to be attendant to the breadth of modes of genealogical discordance. One reason for that is the danger of over-attributing the presence of discordance to one of these modes. For example, if high levels of genealogical discordance were discovered in a system, yet only HGT considered as an explanation for the presence of this discordance, then the level of HGT might be over-estimated for that system (and other explanations under-estimated). This threatens to obscure the role other modes of production of genealogical discordance played in the history of that system (Galtier and Daubin 2008; Haber 2012). Another reason to be attendant to the various modes of genealogical discordance is the opportunity it presents. Different modes of genealogical discordance produce different patterns of discordance. As researchers better identify those distinct patterns and build models of inference that take advantage of this, we are in a better epistemic position to report on the complex histories of evolutionary systems (e.g., Hailer et al. 2012; Kutschera et al. 2014; Pease et al. 2016).

Methodological considerations are certainly an important component of how genealogical discordance impacts our approach to studying species. Yet, my primary interest here is broader than that, and in the next section I consider this through three framing questions that set research problems for how we think about species.

\section{Species in the Age of Discordance}

Merely asking how genealogical discordance impacts our study of species is too imprecise. There are so many ways to think about species, let alone how we might study them, that we need to introduce some structure to usefully move forward. Here I use three framing questions to facilitate that goal:

- How, if at all, does genealogical discordance challenge, modify, or revise how we conceive of species? 
- How has growing appreciation of genealogical discordance impacted scientific practice? Of systematics in particular?

- How do lineages at different levels diverge and diversify?

These framing questions are intended to produce more precise questions around the study of species-questions that, in turn, identify opportunities and challenges that researchers are (or ought to be) exploring. For the first two, I use specific examples to highlight how an appreciation for genealogical discordance complicates and, in many cases, enriches the way we interrogate biological divergence and diversification. For the third framing question, I take the opportunity to be more speculative.

\subsection{Discordant Species}

Let's start with the big picture: genealogical discordance challenges the very notion of what a species is, or whether it even makes sense to include anything like species in our ontology. ${ }^{6}$

At least at a broad level, discordance can be viewed as challenging the very notion of coherently discrete or distinct taxonomic groups in biology at all. To see why, let's go back to Darwin's Origin of Species (1964). Darwin included only a single figure in his Origin (figure 4) - a figure

$\begin{array}{r}a^{14} q^{14} p^{14} \\ \hline\end{array}$

Figure 4: Darwin's Phylogeny (Darwin [1859] 1964). Public domain, from Wikimedia Commons, licensed under CC BY-SA 3.0.

which may be interpreted in lots of ways (and was, even by Darwin!). One way Darwin uses this figure is to answer the question of why we don't see continuous variation, but instead see

6. O'Hara (1993) was among the first to recognize how genealogical discordance challenged the very framing of what is typically called the species problem. He concluded that the species problem was not something to solve, but to "get over." The ensuing years have vindicated his account.

๑ OPEN ACCESS - PTPBIO.ORG 
distinct groups of entities in biology (Darwin [1859] 1964). This figure helps him explain how, in a system of descent with modification, processes of divergence and diversification, coupled with selection, generate distinct groups. One natural reading of that is to treat those groups that are products of those processes as taxa (typically species, but the reading may hold at other levels of hierarchy too).

Notoriously, fleshing out precisely what sorts of groups of organisms should be treated as species has been an ongoing source of disagreement. Just looking at Darwin's figure, for example, we might disagree on how inclusive we ought to be in grouping those products together as a species. We also might disagree over what criteria we ought to use to determine which groups are groups of species (as opposed to other kinds of groups), e.g., we might apply a principle of interbreeding, or genetic exchange, or occupation of a shared ecological niche, or shared common descent, etc.; sometimes these groupings will align, other times not. We might be committed to a prospective approach that groups together as a species those things that we think will continue to persist as groups; in contrast, adopting a retrospective approach identifies as a species those groups that have historically held together by some specified criteria (Harrison 1998).

That is just a sampling of the many dimensions along which debates over the so-called species problem can take shape, though I have no interest in rehashing that here (see Wilkins 2009, for a more exhaustive analysis). Instead, in this section I want to make the case that genealogical discordance makes the species problem harder; it complicates and muddies that debate by troubling what has been a background assumption of much of that debate. Let's call this the D\&D assumption: that evolutionarily divergent lineages will be both distinctive (as a group) and discrete (from other groups). The way genealogical discordance complicates this assumption takes us back to where we began, to Phil Ward's question of whether the branches of our phylogenetic trees are too thin, and, in this context, encourage us to treat groups as more discrete than they are.

Genealogical discordance challenges the underlying assumption that evolution is generating singular distinct and discrete groups as the products of evolution. To see this, consider again figure 4, and how we might consider - in light of genealogical discordance-Darwin's question of why there are discrete groups rather than continuous variation in an evolutionary system. Namely, do we still see discrete groups in the context of a system that also exhibits enormous amounts of discordance? What kinds of groups do we see in a system like this? In what way are they meaningfully discrete? What if multiple groups are being generated that are overlapping with one another in complex and interesting ways, perhaps even overlapping in dynamic ways if we introduce a temporal element? This may mean that the groupings we identify are multifaceted and complex in peculiar and surprising ways, but in ways that reflect the processes of divergence and diversification that we are hoping to study and understand (see figure 5). That's pretty exciting, but it also means we may need to re-conceive just what sorts of groups we ought to be looking for and including in our ontology, e.g., multidimensional objects that are multiply decomposable and overlapping with other groups (Haber 2012; Conix 2018; Sterner, forthcoming); or treating taxa as probabilistic clouds rather than as concrete categorical objects (Maddison 1997). Clarke (2012) describes an analogous and adjacent issue as a 'counting problem'; genealogical discordance complicates this problem, perhaps exponentially.

There's a lot going on here, and to avoid getting bogged down in some of the details of the debate I am going to keep the discussion at a bit of a high level while directing readers to where the specifics of those debates may be pursued. Roughly: the D\&D assumption is that divergent lineages will be distinctive (as a group) and discrete (from other groups), and that this will be reflected in species by an internal cohesion of parts that recurs over generational time. As with 


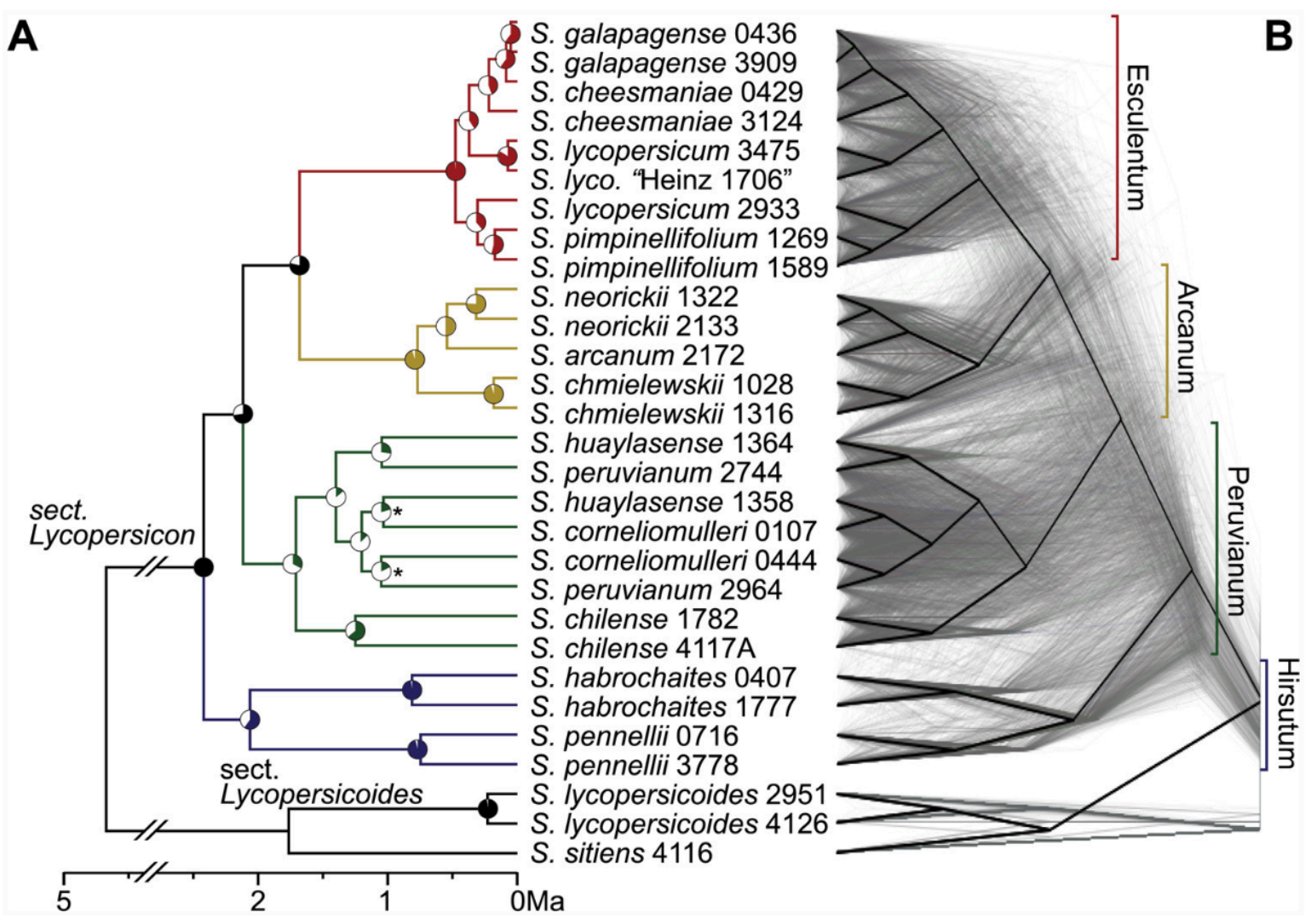

Figure 5: Incorporating genealogical discordance into systematic studies reveals complexity and details otherwise obscured, e.g., including ILS in the analysis of the wild tomato clade (Pease et al. 2016, 5, figure 2). This demonstrates the utility of taking seriously Phil Ward's question of whether the branches of phylogenetic trees are too thin, e.g., studies like these across a broad range of taxa and clades may provide data to test hypotheses about macroevolutionary trends, e.g., whether plants evolve differently than animals (Jablonski 2017b). Figure copyright 2016 Pease et al., distributed under CC BY 4.0.

all things species, there are, of course, debates over what it means for a species to be cohesive, and what that implies for what kinds of things species are. Those debates concern the epistemic criteria for grouping (e.g., Cracraft 1992; Coyne and Orr 2004), the ontology of species (Barker and Wilson 2010; Neto 2016), and how these activities are related on a diachronic scale (Queiroz 2007).

Franklin (2007) provides a good example of how genealogical discordance complicates the D\&D assumption and takes us back to the first framing question (of how genealogical discordance challenges our very conception of species). Franklin considers what species concepts might apply to bacteria, with special attention paid to how discordance undermines applications of these concepts to microbial systems: "the occurrence of HGT undercuts claims that gene exchange is responsible for unifying population lineages, as well as throwing into doubt our understanding of just what these lineages are" (70). This echoes similar sentiments voiced by many microbiologists (though see Galtier and Daubin 2008, for a dissenting view).

We can read Franklin's argument as noting that genealogical discordance (especially HGT) works against the emergence of distinctive and discrete groups at a level we would typically identify as species. One response that may be offered to this is to observe that there are multiple mechanisms working for and against the emergence of such groups, and that the expression of 
those various mechanisms (and their balance against one another) is far from universal across clades. This suggests that the distinctiveness and discreteness of groups or levels of hierarchy is an evolved feature of biological hierarchies that might not be expressed uniformly across the entirety of biology. That is, 'species' as a level of lineage or group is an evolved character of biological lineages and clades (Haber 2016) (and, where that level did emerge, it may have done so in very different ways). Among other things, this supports a rank-free view of that hierarchy (G. C. D. Griffiths 1974; Queiroz and Gauthier 1992; Ereshefsky 2001; Okasha 2011), and, more radically, lends credence to views that the groups that did evolve above the level of organism may not be as similar or uniform as is often supposed (and, thus, may fail to license inferences presuming that similarity) (Mishler 1999).

Franklin's (2007) observation notwithstanding, variation across biology is not continuous, and there are meaningfully distinct groups that reflect underlying biological processes and mechanisms. Yet, these groups are rarely, if ever, categorically and cleanly delineated. Much of that 'messiness' may be measured or expressed in terms of genealogical discordance, and this complicates how we determine which groups are meaningful groups at all, let alone species. Precisely how genealogical discordance will shape the species debate is still an open question. But it is a question that offers a rich research opportunity, and a sophisticated, nuanced treatment.

The upshot is that traditional, or, at least, naive accounts of what taxonomic groups are will be unlikely to survive as relevant or useful treatments in light of discordance. However, it would be a mistake to think this entails the dissolution of meaningful groupings at all in biology. Groups must be understood as complex, dynamic, and multi-dimensional, but that, in turn, leads to a far richer understanding of evolutionary systems. These groups may fail to be natural kinds, ${ }^{8}$ but that hardly means they are not theoretically relevant, causally efficacious, or explanatorily rich. It is, thus, a mistake to think that only groups that are natural kinds, or that present clean categorical boundaries, are groups worth tracking, naming, or classifying (e.g., G. C. D. Griffiths 1974; Gauthier 1986; Queiroz 2007; Ereshefsky 2007; Haber 2016).

\subsection{Scientific Practice}

How has growing appreciation of genealogical discordance impacted scientific practice? Of systematics in particular? In this section I offer one answer to these questions, making the case that genealogical discordance pushes us to revise a centrally important methodological commitment in phylogenetics. To help see this, let's start with an example.

Lin et al. (2010) compare six competing views on the phylogeny of Pinaceae genera and subfamilies (figure 6). These phylogenetic hypotheses are in conflict, i.e., they display discordant genealogical branching patterns. The traditional approach in cases like this is to resolve that conflict, understood as identifying which one of the available hypotheses is the best supported.

That is hardly surprising, and follows from the central commitments of phylogeny reconstruction. Felsenstein (1988) states this with characteristic clarity, putting it plainly:

If each site in a set of sequences has changed only once in the evolution of a group, then the newly-arisen base will be shared by all species descended from the lineage in which the change occurred. If this were the case at all sites, then the sets of species

7. Haber (2013) suggests that Mishler's point may hold for organisms as well.

8. Unless, of course, these groups are taken to be paradigmatic natural kinds, which instead entails revisions to traditional accounts of natural kinds. Boyd (1999), P. E. Griffiths (1999), and Slater (2015), among others, adopt this sort of strategy in developing their accounts of natural kinds. See Haber (2016) for a taxonomy of views around natural kinds.

9. Or corroborated, if you hold to a particular philosophy of phylogenetic inference (Editors 2016).

○ OPEN ACCESS - PTPBIO.ORG 
A

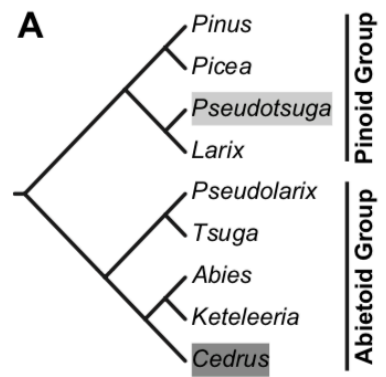

Price (1987)

(immunology)

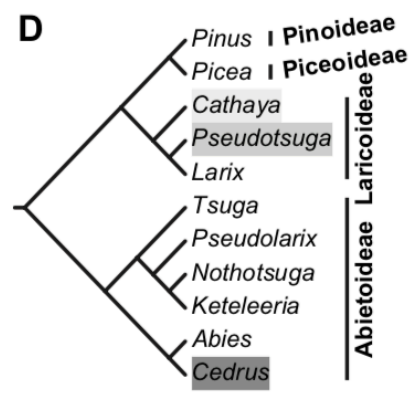

Farjon (1990)

(morphology)

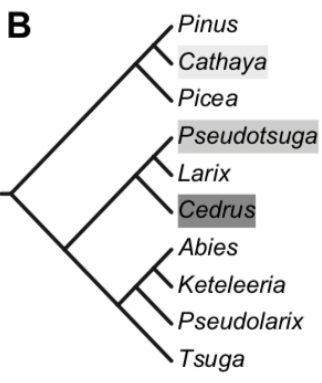

Hart (1987)

(morphology)

E

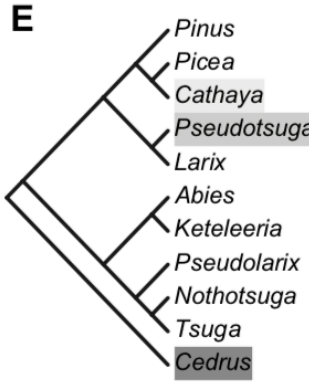

Wang et al. (2000) (nad5, matK, and 4CL)

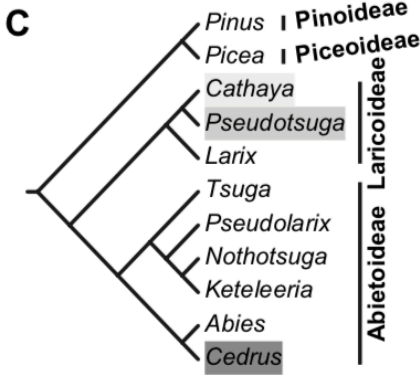

Frankis (1988) (morphology)

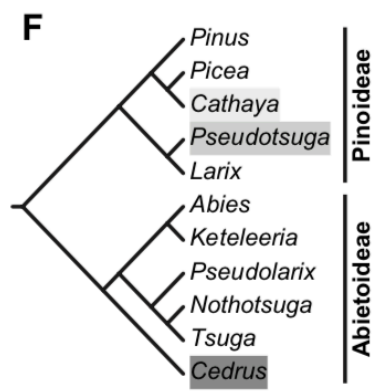

Gernandt et al. (2008)

(Morphology, fossil, matK and $r b c L$ )

Figure 6: Pinaceae phylogeny (Lin et al. 2010, 505, figure 1, distributed under CC BY-NC).

having the new bases would be either perfectly nested or disjoint, never overlapping unless one set of species was included in the other. It would be possible to erect a tree on which we could explain the evolution of the group with only a single change at each site. This can be done by inspection of the sets of species defined at each varying site. If some of these sets of species overlap without being nested, then there is conflict between the information provided by different sites. Most of the interesting issues in phylogeny reconstruction are in how to resolve these conflicts. (524, emphasis added)

The conflict described here by Felsenstein covers a lot of kinds of conflict we see in phylogenetics (though, as is hopefully clear by now, not all the kinds of conflicts). Regardless, the highlighted part of this passage captures an important commitment in phylogenetic inference, that the central task is to resolve conflicting phylogenetic signals. Traditionally, this has meant identifying the single best-supported tree.

That is certainly an important methodological commitment about the goal of phylogenetic analysis, and not one I am disputing here. However, I am suggesting that it needs to be revised in light of discoveries that the breadth and depth of genealogical discordance is far greater than anticipated-so much so that genealogical discordance ought to be regarded as simply a background feature of most, if not all, evolving systems. That is, I am proposing that this commitment of phylogeny reconstruction be revised as follows: "most of the interesting issues in phylogeny reconstruction are in how to resolve or reconcile these conflicts." 10

10. This follows Nakhleh (2013), who uses reconcile or reconciliation to describe cases where genealogical discordance is the product of one of the modes described above. 
The change this revision implies is subtle but impactful. When faced with conflicting information about phylogenies, phylogeneticists now must consider two different possible kinds of explanations. On the one hand, the conflict might be resolved in favor of one or the other phylogenies. This involves testing competing phylogenetic hypotheses for that which is best supported (on competing models of phylogenetic inference). This approach reflects the methodological commitment as previously understood (and articulated by Felsenstein). 11

On the revised commitment, and in recognition of genealogical discordance, phylogeneticists should also consider whether the conflict might be reconciled as reflecting the outcome of genealogical discordance; i.e., whether the conflict is a product of the underlying processes of lineage generation that can produce discordance. That is, that the conflicting patterns correctly reflect the multiple histories a complex lineage might contain.

This is not to criticize Lin et al. (2010). I have no evidence nor have I analyzed their data to determine whether a discordant explanation of reconciliation better explains the data than resolving the conflict; on the contrary, the study looks like a model of careful, good work that nicely reflects the central methodological commitments of phylogenetics. Rather, it is a testament to how quickly science can shift that a study done in 2010 can now be viewed as working in a rather narrower framing question than we might now expect.12

An appreciation of genealogical discordance complicates what was a reasonable methodological commitment less than a decade ago. It is an example of a shift in commitments in a research community, and, I believe, how our expectations of scientific methodology may advance or progress in response to empirical discoveries as well as conceptual and theoretical advances. Because it enriches our understanding of evolutionary systems and explains a greater amount of data in response to disruptive challenges, I call advances like these productive disruptions.

Advances in our understanding of genealogical discordance mean that a study like Lin et al.'s (2010) now include the possibility that what appear to be conflicts may be reconciled by appeal to genealogical discordance. Hailer et al. (2012) do just this in their study of polar bears (figure 7). The conflict between mtDNA and nDNA is reconciled by appeal to a hypothesized hybridization event; i.e., they provide an alternative (reconciliation) explanation which includes genealogical discordance, rather than an (resolving) explanation that explains away the discordant phylogenies in favor of one tree, and the explanation is richer for it. Similarly, Willyard, Cronn, and Liston (2009) argue that patterns of incongruence in ponderosa pine nDNA and chloroplast haplotypes are best explained by introgression followed by a genetic bottleneck (rather than incomplete lineage sorting, or other modes of genealogical discordance), concluding that single-locus analyses risk missing these biologically relevant patterns. Pease et al. (2016) (figure 5) provide another example of the richness of adopting a broader framing question, though in this case it is incomplete lineage sorting (rather than introgression) that provides that richer and more complex explanation. These represent marked shifts in how apparent conflicts in phylogenetic signals are considered by researchers over the past decade. ${ }^{13}$

To be very clear, this is not a call to reject the methodological commitment of resolving conflict (selecting one hypothesis over another). This remains a deeply important and fruitful approach to phylogenetic analysis, and I am not calling for it to be abandoned in favor of looking to explain conflict as the product of genealogical discordance. Rather, it is a matter of being

11. Notably, nothing in Felsenstein (1988) rules out the expanded sense of this commitment, and he is certainly aware of it (and only more so as genealogical discordance has become more generally recognized).

12. Revisiting previous phylogenetic hypotheses using new methods and/or new data is standard practice in systematics. Indeed, the same lab did just this for Pinaceae (Sudianto et al. 2016).

13. These examples are, arguably, exemplars of Lloyd's (2015) characterization of how the logic of the research question can limit or enrich scientific studies. 

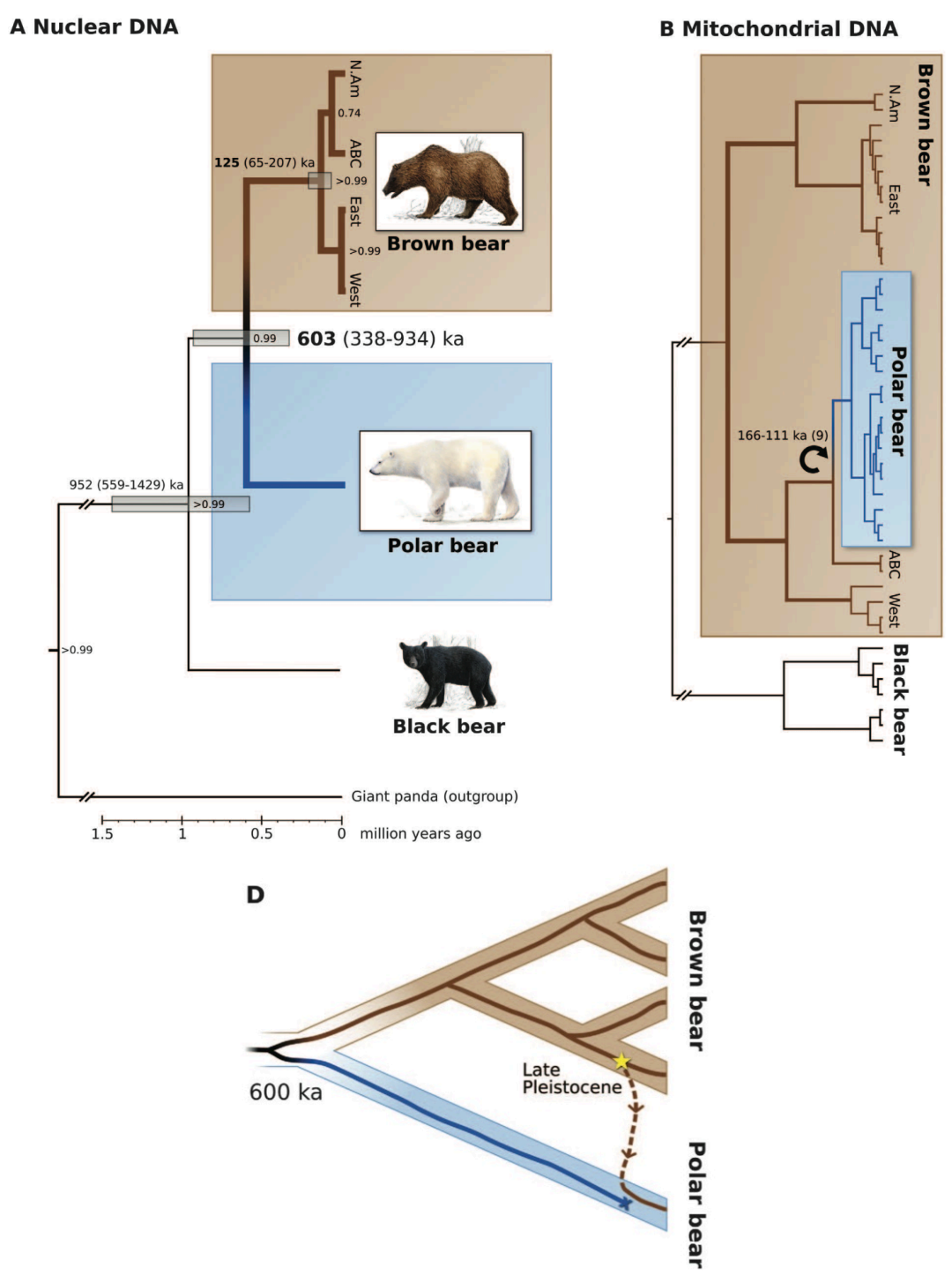

Figure 7: In explaining the apparent conflict between mtDNA and nDNA in polar bear phylogenies, Hailer et al. (2012) embody the employment of reconciliation rather than resolving strategies. The availability of these different modes of explanation represent an expansion of a central commitment of phylogenetic inference. From Hailer et al. 2012, 345, figure 1a, b, d, reprinted with permission from AAAS.

sensitive to the sorts of conditions underlying potential conflicts, and applying the right sorts of methodological and analytical tools to identify explanations for those incongruences. 14

Incongruence between molecular and morphological data, for example, may be explained as the result of convergent evolution. In those sorts of cases, molecular data may better reflect resemblance due to common descent, as opposed to resemblance due to convergent evolutionary pressures, and resolving (rather than reconciling) the conflicting data might be justified (Moore and Willmer 1997; San Jose et al. 2018). In other cases, the underlying patterns of incongruence may suggest a mechanism of genealogical discordance. A methodological challenge is identify-

14. This is reminiscent of previous episodes of methodological advancements in phylogenetics. For example, Felsenstein (1978) famously identified conditions under which parsimony methods would return positively misleading errors. Hillis, Huelsenbeck, and Cunningham (1994), among others, tested this observation using empirical and simulation studies. Much of the recent literature exploring genealogical discordance and phylogenetic inference can be understood in the same vein (e.g., Degnan and Rosenberg 2006). 
ing what patterns of conflict are good candidates for reconciliation (as products of genealogical discordance) or resolving (in favor of one phylogenetic pattern over others). Degnan and Rosenberg (2006) do just this, identifying patterns and conditions characteristic of incomplete lineage sorting.

Much more could be said about how genealogical discordance impacts phylogenetic methods for investigating species relationships. In an important sense, the revision I propose here is not an abandonment of the goal of identifying the best-supported tree. It's just to expand what might count as a best supported tree, and to include trees exhibiting discordance among that group. As the polar bear and tomato cases demonstrate, the upshot is a richer account of speciation, divergence, and diversification.

\subsection{Lineage Divergence and Diversification}

One way to think about the field of systematics is as a field concerned with investigating the divergence and diversification of lineages. In this section I aim to explore a bit how genealogical discordance impacts that investigation.

Simply put, genealogical discordance can play a biologically significant role in the history of a biological system, and that role will be reflected in the patterns and products of divergence and diversification of that system. Identifying those products and reconstructing those patterns provide important data as we seek to understand that system. The different modes of genealogical discordance involve a wide range of biological patterns and processes, ranging from those found in population genetics (e.g., ILS), to development (e.g., gene duplication and loss; recruitment of exogenous parts; symbiosis), to ecological factors (e.g., hybridization; niche and epigenetic inheritance). The upshot is that the study of genealogical discordance acts, in many ways, as the nexus of different fields of biology. ${ }^{15}$ Let's unpack this a bit.

The previous two sections considered how genealogical discordance impacts taxonomic and phylogenetic projects. The former considered how genealogical discordance enriches and complicates our taxonomic ontology; the latter how it enriches and complicates the practice of reconstructing phylogenies. These phylogenetic and taxonomic projects, though, are not independent of one another, and it will be helpful to recast the response to the framing questions of those sections with that in mind.

To wit, phylogenetic inference is about patterns, but patterns of what? Traditionally, of species, but, as described in $\$ 3.1$, phylogeneticists have grown far more sophisticated about this (and wary, as questions about what species are can easily grow into distractions). Moreover, tracking gene lineages against population-level lineages (among other contrasting lineages) has revealed important patterns of diversification and divergence that might otherwise be obscured.

One way we might usefully reframe the question 'What we are tracking patterns of?' is by simply noting that we are tracking the patterns of the units of divergence and diversification, whatever those units may end up being (and without defining them ahead of time). Moreover, these units of divergence and diversification may be parts of other units, ${ }^{16}$ which may in turn be: taxonomic units; units of selection, or evolution, or development; or themselves units of divergence and diversification, etc. Which units are of interest will depend on what questions we are pursuing, what systems we are studying, and what level of resolution we think is relevant to those research programs (O'Hara 1993).

15. Minelli (2009) describes something like this in what he calls a 'Phylo-evo-devo' approach; see Laurin and Germain (2011) and Kin et al. (2015) for examples putting this approach into practice (though they are not described in detail here). Likewise, Jablonski (2017a, 2017b) recognizes how an integrated approach like this is central to the study of macroevolutionary trends, e.g., the origin and sorting of variation across clades.

16. Indeed, it may be that they must be parts of other units.

๑ OPEN ACCESS - PTPBIO.ORG 
One lesson we ought to take from genealogical discordance is that we must be sophisticated about when we may treat units of divergence and diversification as simple proxies for the larger units that they are a part of; if those more inclusive units are complex multilevel lineages, for example, than treating their parts as simple proxies may obscure important features and histories of those more inclusive units. The lineages that are parts of those units will not necessarily track each other faithfully. In this way, genealogical discordance is a feature of the ways the parts and wholes of biological lineages relate to one another through the different processes of divergence and diversification.

We can return to the framing question for this section identified at the beginning of this paper: "How do lineages at different levels diverge and diversify?" There won't be a simple answer to this, but we are now in a position to recognize that genealogical discordance will play a central role in how we respond to it, and enrich our understanding and study of divergence and diversification. Increasingly, this also requires working at the interface of multiple fields of biology, because units of divergence and diversification are found across levels and scales of biology.

This is exciting. It requires bringing together evolutionary, developmental, and phylogenetic approaches (at least). Examples of this are emerging, and it's helping to advance theoretical, empirical, and conceptual work in biology. This might include something as straightforward as applying phylogenetic methods to developmental biology, which may be used to reciprocally illuminate studies of ontogeny as well as refine phylogenetic methods (e.g., Salipante and Horwitz 2006; Laurin and Germain 2011). Or it may be a deeper integration of fields that fuse approaches for investigating units and patterns of divergence and diversification to interrogate and reframe research problems at the intersection of different disciplines.

Arendt et al. (2016) provide a good example of how this integrated approach may be embodied to provide foundational conceptual resources. Their review of cell type evolution treats cell types as "evolutionary units" that may be developmentally expressed in a broad range of organisms. They argue that this is "analogous to the conceptual transition from Linnean [sic] to evolutionary classification at the species level and should be equally beneficial" (754). Though Arendt et al. see payoffs in comparative cell biology, and the development of tools to facilitate tracking cell types across and within species, they also see a broad range of rich research problems stemming from their approach that employ the very same conceptual and methodological issues discussed here around genealogical discordance. Indeed, this is particularly notable in their recognition of how understanding discordance can help illuminate both the units and patterns of divergence and diversification found in comparative cell biology:

Another challenging area is the co-analysis of cellular identity and developmental lineage. Our model of sister cell type evolution suggests that there can be discordance between evolutionary and developmental lineage. To understand this discordance will require the careful distinction of cell types across different developmental stages and lineages. (755)

Liebeskind et al. (2017, see figure 8) employ the Arendt et al. model of cell-type evolution, demonstrating how genealogical discordance presents an opportunity for novel advancement at the interface of disciplines. In this case, it is teams of biologists from different disciplines collaborating and using the patterns of discordance between evolutionary and developmental lineages to investigate the evolution of animal neural tissue. 


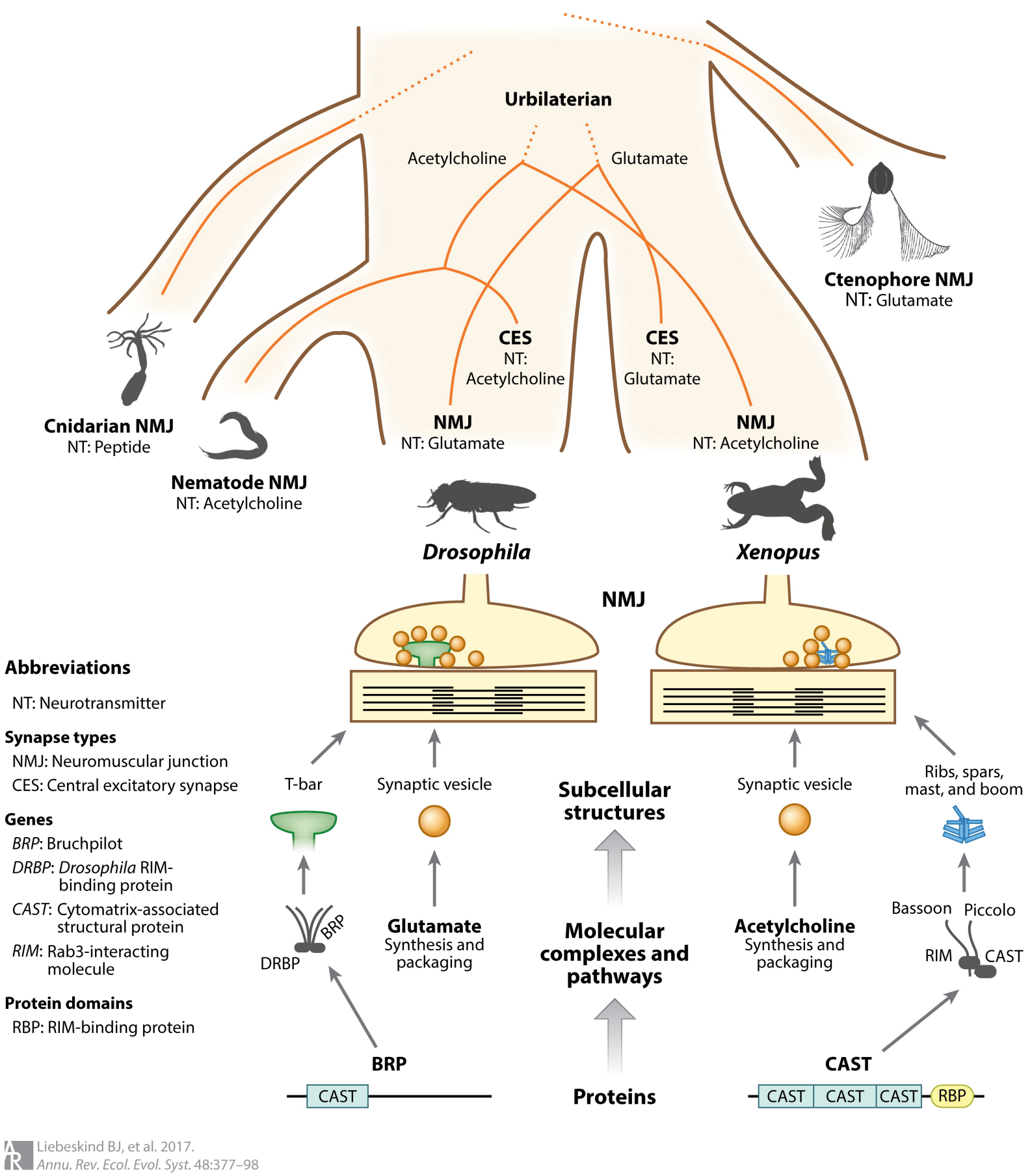

Figure 8: Genealogical discordance of the expression of cell type differentiation and population lineages reveals insights about the evolution of the development of specialized tissues (in this case animal neural tissue). From Liebeskind et al. (2017, 392, figure 6, reproduced with permission of Annual Reviews via Copyright Clearance Center).

These and other sorts of questions about divergence and diversification of lineages at different levels may also provide data for studying the generation and sorting of variation within and across clades. Whether different modes and patterns of genealogical discordance are differentially expressed in different clades is an empirical, macroevolutionary question about trends of divergence and diversification. Identifying those cross-clade patterns requires a synthetic ex- 
amination across multiple fields of biology (see Jablonski 2017a, 2017b), as would potential systematic explanations of those patterns.

This is all to suggest that the framing question for this section, "How do lineages at different levels diverge and diversify?," is really at the intersection of the previous two sections. Though this section is a bit more speculative than the prior two, there are already good indications that genealogical discordance is functioning as a fruitful nexus for integrated approaches to studying divergence and diversification across scales and levels of biology.

\section{Summary \& Conclusion}

This paper began by recalling Phil Ward's question, "Are the branches of phylogenetic trees too thin?" I presented this as a prompt to pay attention to the internal structure of lineages, and what that might tell us about systems of divergence and diversification. Ward's question was prescient, as I aimed to demonstrate by considering how the growing appreciation for genealogical discordance has impacted our study of species. To do this, I used three framing questions:

- How, if at all, does genealogical discordance challenge, modify, or revise how we conceive of species?

- How has growing appreciation of genealogical discordance impacted scientific practice? Of systematics in particular?

- How do lineages at different levels diverge and diversify?

To the first of these, genealogical discordance makes the species problem harder. It complicates and muddies taxonomic ontology by troubling what has been a background assumption of much of that debate: that the products of divergence and diversification are straightforwardly distinctive and discrete groups. Instead, we are discovering that the breadth and scope of genealogical discordance is far greater than might have been appreciated a generation ago. However, it would be a mistake to think that this entails there are no meaningful groups or groupings in taxonomy. Rather, it requires a sophisticated approach to one of Darwin's framing questions: Why don't we see continuous variation in nature? In light of genealogical discordance, I suggested that interrogating this research question demands treating taxonomic groups as complex, dynamic, multi-dimensional lineages, and that this, in turn, leads to a far richer understanding of evolutionary systems.

An appreciation for the internal structure of lineages is also providing rich opportunities for advancement in phylogenetic inference. Different modes of genealogical discordance generate distinctive patterns that we are increasingly able to identify and use as data for more precise and richer phylogenetic reconstructions. This amounts to a revision of a centrally important methodological commitment in phylogenetics. Namely, when faced with conflicting data, phylogeneticists should consider whether that conflict may be reconciled by appeal to genealogical discordance, in addition to the traditional strategy of resolving that conflict in favor of one tree or another. This is an expansion of explanatory strategies available to phylogeneticists that has the potential to generate hypotheses that more precisely reconstruct the internal structures of phylogenies. This expansion of explanatory strategies provides phylogeneticists with new sets of tools for reconstructing multilevel patterns of divergence and diversification. 
Taken together, this means that genealogical discordance enriches and complicates our taxonomic ontology, as well as the practice of reconstructing phylogenies. The different modes of genealogical discordance involve mechanisms and processes across the scales and levels of biology. This means that the patterns and products generated by these modes are going to be expressed at the intersection of many fields of biology, from developmental biology to macroevolution. Gaining a greater understanding of genealogical discordance means drawing on these different fields in order to refine our phylogenetic methods and to sharpen how we conceive of the units of divergence and diversification. In turn, these tools and resources are being employed in integrated multidisciplinary studies across biology. This is a good thing, and it presents new avenues for advancement in phylogenetics, while pressing us to reframe some of the central questions and commitments of phylogenetics.

Biology is messy. We rarely find categorical boundaries or clean, isolated processes. That can make it difficult for biologists, because it is often strategically wise to isolate the systems we seek to study, and to simplify the research questions we pursue. To recognize discordance is to recognize that this messiness is amplified. Yet this is also a great opportunity for biologists, and it is worth pausing to appreciate the new conceptual and methodological tools being developed that will continue to advance our understanding of these complex systems.

\section{Acknowledgments}

Support for this project came from the National Science Foundation (award \#1557117, "Evolution and the Levels of Lineage"). Thanks also to the University of Utah Department of Philosophy, Dan Molter, Aleta Quinn, and the University of Utah Philosophy of Biology Lab.

\section{Literature cited}

Arendt, Detlev, Jacob M. Musser, Clare V. H. Baker, Aviv Bergman, Connie Cepko, Douglas H. Erwin, Mihaela Pavlicev, et al. 2016. "The Origin and Evolution of Cell Types." Nature Revierws Genetics 17 (12): 744-757. doi:10.1038/nrg.2016.127.

Avise, John C., and Terence J. Robinson. 2008. "Hemiplasy: A New Term in the Lexicon of Phylogenetics.” Systematic Biology 57 (3): 503-507. doi:10.1080/10635150802164587.

Avise, John C., and Kurt Wollenberg. 1997. "Phylogenetics and the Origin of Species." Proceedings of the National Academy of Sciences 94 (15): 7748-7755. doi:10.1073/pnas.94.15.7748.

Barker, Matthew J., and Robert A. Wilson. 2010. "Cohesion, Gene Flow, and the Nature of Species." The Journal of Philosophy 107 (2): 59-77. doi:10.5840/jphil201010721.

Bershtein, Shimon, Adrian W. R. Serohijos, Sanchari Bhattacharyya, Michael Manhart, Jeong-Mo Choi, Wanmeng Mu, Jingwen Zhou, et al. 2015. "Protein Homeostasis Imposes a Barrier on Functional Integration of Horizontally Transferred Genes in Bacteria." PLoS Genetics 11 (10): 125. doi:10.1371/journal.pgen.1005612.

Bolker, Jessica A. 2000. "Modularity in Development and Why It Matters to Evo-Devo." American Zoologist 40 (5): 770-776. doi:10.1093/icb/40.5.770.

Bouchard, Frédéric. 2010. "Symbiosis, Lateral Function Transfer and the (Many) Saplings of Life." Biology and Philosophy 25 (4): 623-641. doi:10.1007/s10539-010-9209-3.

Boyd, Richard. 1999. "Homeostasis, Species and Higher Taxa." In Species: New Interdisciplinary Essays, edited by Robert A. Wilson. Cambridge, MA: MIT Press. 
Brunet, Tyler D. P., and W. Ford Doolittle. 2015. "Multilevel Selection Theory and the Evolutionary Functions of Transposable Elements." Genome Biology and Evolution 7 (8): 2445-2457. doi:10. 1093/gbe/evv152.

Clarke, Ellen. 2012. "Plant Individuality: A Solution to the Demographer's Dilemma." Biology and Philosophy 27 (3): 321-361. doi:10.1007/s10539-012-9309-3.

Conix, Stijn. 2018. "Integrative Taxonomy and the Operationalization of Evolutionary Independence." European Journal for Philosophy of Science 8 (3): 587-603. doi:10.1007/s13194-018-0202-z.

Coyne, Jerry A., and H. Allen Orr. 2004. Speciation. Sunderland, MA: Sinauer Associates, Inc.

Cracraft, Joel. 1992. "The Species of the Birds-of-Paradise (Paradisaeidae): Applying the Phylogenetic Species Concept to a Complex Pattern of Diversification." Cladistics 8 (1): 1-43. doi:10.1111/j. 1096-0031.1992.tb00049.x.

Darwin, Charles. (1859) 1964. On the Origin of Species. First ed. (facsimile). Cambridge, MA: Harvard University Press.

Degnan, James H., and Noah A. Rosenberg. 2006. "Discordance of Species Trees with Their Most Likely Gene Trees.” PLoS Genetics 2 (5): e68. doi:10.1371/journal.pgen.0020068.

Degnan, James H., and Noah A. Rosenberg. 2009. "Gene Tree Discordance, Phylogenetic Inference and the Multispecies Coalescent." Trends in Ecology and Evolution 24 (6): 332-340. doi:10.1016/j. tree.2009.01.009.

Doolittle, W. Ford. 1999. "Phylogenetic Classification and the Universal Tree." Science 284 (5423): 2124-2128. doi:10.1126/science.284.5423.2124.

Doolittle, W. Ford, and Austin Booth. 2017. "It's the Song, Not the Singer: An Exploration of Holobiosis and Evolutionary Theory." Biology and Philosophy 32 (1): 5-24. doi:10.1007/s10539-0169542-2.

Editors, The. 2016. “Editorial.” Cladistics 32 (1): 1. doi:10.1111/cla.12148.

Ereshefsky, Marc. 2001. The Poverty of the Linnaean Hierarchy. Cambridge: Cambridge University Press. doi:10.1017/CBO9780511498459.

Ereshefsky, Marc. 2007. “Foundational Issues Concerning Taxa and Taxon Names.” Systematic Biology 56 (2): 295-301. doi:10.1080/10635150701317401.

Ereshefsky, Marc. 2010. "Microbiology and the Species Problem.” Biology and Philosophy. doi:10.1007/ s10539-010-9211-9.

Felsenstein, Joseph. 1978. "Cases in Which Parsimony or Compatibility Methods Will Be Positively Misleading.” Systematic Zoology 27 (4): 401-410. doi:10.2307/2412923.

Felsenstein, Joseph. 1988. "Phylogenies from Molecular Sequences: Inference and Reliability." Annual Review of Genetics 22 (1): 521-565. doi:10.1146/annurev.ge.22.120188.002513.

Franklin-Hall, L. R. 2010. “Trashing Life's Tree.” Biology and Philosophy 25 (4): 689-709. doi:10.1007/ s10539-010-9219-1.

Franklin, L. R. 2007. “Bacteria, Sex, and Systematics.” Philosophy of Science 74 (1): 69-95. doi:10.1086/ 519476.

Galtier, Nicolas, and Vincent Daubin. 2008. "Dealing with Incongruence in Phylogenomic Analyses." Philosophical Transactions of the Royal Society B: Biological Sciences 363 (1512): 4023-4029. doi:10. 1098/rstb.2008.0144. 
Gauthier, Jacques. 1986. "Saurischian Monophyly and the Origin of Birds." In The Origin of Birds and the Evolution of Flight, edited by Kevin Padian. Memoirs of the California Academy of Sciences 8. San Francisco, CA: California Academy of Sciences.

Griffiths, Graham C. D. 1974. "On the Foundations of Biological Systematics." Acta Biotheoretica 23 (3): 85-131. doi:10.1007/bf01556343.

Griffiths, Paul E. 1999. "Squaring the Circle: Natural Kinds with Historical Essences." In Species: New Interdisciplinary Essays, edited by Robert A. Wilson, 209-28. Cambridge, MA: MIT Press.

Haber, Matthew H. 2012. "Multilevel Lineages and Multidimensional Trees: The Levels of Lineage and Phylogeny Reconstruction.” Philosophy of Science 79 (5): 609-623. doi:10.1086/667849.

Haber, Matthew H. 2013. "Colonies Are Individuals: Revisiting the Superorganism Revival." Chap. 9 in From Groups to Individuals: Evolution and Emerging Individuality, edited by Frédéric Bouchard and Philippe Huneman. MIT Press.

Haber, Matthew H. 2016. “The Individuality Thesis (3 Ways).” Biology and Philosophy 31 (6): 913-930. doi:10.1007/s10539-016-9548-9.

Hailer, Frank, Verena E. Kutschera, Björn M. Hallström, Denise Klassert, Steven R. Fain, Jennifer A. Leonard, Ulfur Arnason, et al. 2012. "Nuclear Genomic Sequences Reveal That Polar Bears Are an Old and Distinct Bear Lineage.” Science 336 (6079): 344-347. doi:10.1126/science.1216424.

Harrison, Ellie, David Guymer, Andrew J. Spiers, Steve Paterson, and Michael A. Brockhurst. 2015. "Parallel Compensatory Evolution Stabilizes Plasmids across the Parasitism-Mutualism Continuum.” Current Biology 25 (15): 2034-2039. doi:10.1016/j.cub.2015.06.024.

Harrison, Richard G. 1998. "Linking Evolutionary Pattern and Process: The Relevance of Species Concepts for the Study of Speciation." Chap. 2 in Endless Forms: Species and Speciation, edited by Daniel J. Howard and Stewart H. Berlocher. Oxford University Press.

Hejnol, Andreas, and Christopher J. Lowe. 2015. "Embracing the Comparative Approach: How Robust Phylogenies and Broader Developmental Sampling Impacts the Understanding of Nervous System Evolution." Philosophical Transactions of the Royal Society B: Biological Sciences 370 (1684): 20150045. doi:10.1098/rstb.2015.0045.

Hennig, Willi. 1966. Phylogenetic Systematics. Urbana and Chicago: University of Illinois Press.

Hillis, David M., John P. Huelsenbeck, and Clifford W. Cunningham. 1994. "Application and Accuracy of Molecular Phylogenies.” Science 264 (5159): 671-677. doi:10.1126/science.8171318.

Howard, Daniel J., Pamela G. Gregory, Jiming Chu, and Michael L. Cain. 1998. "Conspecific Sperm Precedence Is an Effective Barrier to Hybridization between Closely Related Species." Evolution 52 (2): 511-516. doi:10.1111/j.1558-5646.1998.tb01650.x.

Hudson, Richard R. 1983. "Testing the Constant-Rate Neutral Allele Model with Protein Sequence Data." Evolution 37 (1): 203-217. doi:10.2307/2408186.

Huneman, Philippe. 2013. “Developmental Module.” In Encyclopedia of Systems Biology, edited by Werner Dubitzky, Olaf Wolkenhauer, Kwang-Hyun Cho, and Hiroki Yokota. New York, NY: Springer. doi:10.1007/978-1-4419-9863-7_934.

Jablonka, Eva, and Marion J. Lamb. 2014. Evolution in Four Dimensions: Genetic, Epigenetic, Behavioral, and Symbolic Variation in the History of Life. Revised. MIT Press.

Jablonski, David. 2017a. “Approaches to Macroevolution: 1. General Concepts and Origin of Variation.” Evolutionary Biology 44 (4): 427-450. doi:10.1007/s11692-017-9420-0. 
Jablonski, David. 2017b. "Approaches to Macroevolution: 2. Sorting of Variation, Some Overarching Issues, and General Conclusions.” Evolutionary Biology 44 (4): 451-475. doi:10.1007/s11692017-9434-7.

Johnson, Kevin P., Richard J. Adams, Roderic D. M. Page, and Dale H. Clayton. 2003. "When Do Parasites Fail to Speciate in Response to Host Speciation?” Systematic Biology 52 (1): 37-47. doi:1 $0.1080 / 10635150390132704$.

Kin, Koryu, Mauris C. Nnamani, Vincent J. Lynch, Elias Michaelides, and Günter P. Wagner. 2015. "Cell-Type Phylogenetics and the Origin of Endometrial Stromal Cells." Cell Reports 10 (8): 1398-1409. doi:10.1016/j.celrep.2015.01.062.

Kuchta, Shawn R., and David B. Wake. 2016. "Wherefore and Whither the Ring Species?" Copeia 104 (1): 189-201. doi:10.1643/OT-14-176.

Kutschera, Verena E., Tobias Bidon, Frank Hailer, Julia L. Rodi, Steven R. Fain, and Axel Janke. 2014. "Bears in a Forest of Gene Trees: Phylogenetic Inference Is Complicated by Incomplete Lineage Sorting and Gene Flow." Molecular Biology and Evolution 31 (8): 2004. doi:10.1093/ molbev/msu186.

Lacquaniti, Francesco, Yuri Ivanenko, Andrea d'Avella, Karl Zelik, and Myrka Zago. 2013. "Evolutionary and Developmental Modules." Frontiers in Computational Neuroscience 7:61. doi:10.3389/ fncom.2013.00061.

Laland, Kevin N., Tobias Uller, Marcus W. Feldman, Kim Sterelny, Gerd B. Müller, Armin Moczek, Eva Jablonka, et al. 2015. "The Extended Evolutionary Synthesis: Its Structure, Assumptions and Predictions." Proceedings of the Royal Society of London B: Biological Sciences 282 (1813): 20151019. doi:10.1098/rspb.2015.1019.

Laland, Kevin, Tobias Uller, Marc Feldman, Kim Sterelny, Gerd B. Müller, Armin Moczek, Eva Jablonka, et al. 2014. "Does Evolutionary Theory Need a Rethink? Yes, Urgently." Nature 514 (7521): 161-164. doi:10.1038/514161a.

Laurin, Michel, and Damien Germain. 2011. "Developmental Characters in Phylogenetic Inference and Their Absolute Timing Information." Systematic Biology 60 (5): 630-644. doi:10.1093/sysbio/ syr024.

Liebeskind, Benjamin J., Hans A. Hofmann, David M. Hillis, and Harold H. Zakon. 2017. "Evolution of Animal Neural Systems." Annual Review of Ecology, Evolution, and Systematics 48 (1): 377-398. doi:10.1146/annurev-ecolsys-110316-023048.

Lin, Ching-Ping, Jen-Pan Huang, Chung-Shien Wu, Chih-Yao Hsu, and Shu-Miaw Chaw. 2010. "Comparative Chloroplast Genomics Reveals the Evolution of Pinaceae Genera and Subfamilies." Genome Biology and Evolution 2:504-517. doi:10.1093/gbe/evq036.

Linquist, Stefan, Karl Cottenie, Tyler A. Elliott, Brent Saylor, Stefan C. Kremer, and T. Ryan Gregory. 2015. "Applying Ecological Models to Communities of Genetic Elements: The Case of Neutral Theory.” Molecular Ecology 24 (13): 3232-3242. doi:10.1111/mec.13219.

Lloyd, Elisabeth A. 2015. "Adaptationism and the Logic of Research Questions: How to Think Clearly About Evolutionary Causes.” Biological Theory. doi:10.1007/s13752-015-0214-2.

Maddison, Wayne P. 1997. “Gene Trees in Species Trees.” Systematic Biology 46 (3): 523-536. doi:10. $2307 / 2413694$.

Martin, William. 1999. "Mosaic Bacterial Chromosomes: A Challenge en route to a Tree of Genomes.” BioEssays 21 (2): 99-104. doi:10.1002/(SICI)1521-1878(199902)21:2<99::AIDBIES3>3.0.CO;2-B. 
McShea, D. W. 2001. "The Minor Transitions in Hierarchical Evolution and the Question of a Directional Bias." Journal of Evolutionary Biology 14 (3): 502-518. doi:10.1046/j.1420-9101.2001. 00283.x.

Minelli, Alessandro. 2009. "Phylo-Evo-Devo: Combining Phylogenetics with Evolutionary Developmental Biology.” BMC Biology 7 (1): 36. doi:10.1186/1741-7007-7-36.

Mishler, Brent D. 1999. “Getting Rid of Species.” In Species: New Interdisciplinary Essays, edited by Robert A. Wilson, 141-85. Cambridge, MA: MIT Press.

Molter, Dan. Forthcoming. “On Mychorrizal Individuality.” Biology and Philosophy.

Moore, Janet, and Pat Willmer. 1997. "Convergent Evolution in Invertebrates." Biological Revierws 72 (1): 1-60. doi:10.1111/j.1469-185x.1997.tb00009.x.

Moxon, E. Richard, Paul B. Rainey, Martin A. Nowak, and Richard E. Lenski. 1994. “Adaptive Evolution of Highly Mutable Loci in Pathogenic Bacteria." Current Biology 4 (1): 24-33. doi:10. 1016/S0960-9822(00)00005-1.

Nakhleh, Luay. 2013. "Computational Approaches to Species Phylogeny Inference and Gene Tree Reconciliation." Trends in Ecology and Evolution 28 (12): 719-728. doi:10.1016/j.tree.2013.09. 004.

Neigel, Joseph E., and John C. Avise. 1986. "Phylogenetic Relationships of Mitochondrial DNA under Various Demographic Models of Speciation.” In Evolutionary Processes and THeory, edited by Samuel Karlin and Eviatar Nevo, 515-34. Academic Press. doi:https://doi.org/10.1016/B978-012-398760-0.50026-2.

Neto, Celso. 2016. "Rethinking Cohesion and Species Individuality." Biological Theory 11 (3): 138-149. doi:10.1007/s13752-016-0243-5.

Nichols, Richard. 2001. "Gene Trees and Species Trees Are Not the Same." Trends in Ecology and Evolution 16 (7): 358-364. doi:10.1016/S0169-5347(01)02203-0.

O'Hara, Robert J. 1993. “Systematic Generalization, Historical Fate, and the Species Problem.” Systematic Biology 42 (3): 231-246. doi:10.1093/sysbio/42.3.231.

O’Malley, Maureen A. 2014. Philosophy of Microbiology. Cambridge University Press.

O’Malley, Maureen A., William Martin, and John Dupré. 2010. “The Tree of Life: Introduction to an Evolutionary Debate." Biology and Philosophy. doi:10.1007/s10539-010-9208-4.

O’Malley, Maureen, and John Dupré. 2007. “Size Doesn't Matter: Towards a More Inclusive Philosophy of Biology." Biology and Philosophy 22 (2): 155-191. doi:10.1007/s10539-006-9031-0.

Okasha, Samir. 2011. "Biological Ontology and Hierarchical Organization: A Defense of Rank Freedom." Chap. 3 in The Major Transitions in Evolution Revisited, edited by Brett Calcott and Kim Sterelny. MIT Press.

Page, Roderic D. M. 1993. “Genes, Organisms, and Areas: The Problem of Multiple Lineages.” Systematic Biology 42 (1): 77-84. doi:10.2307/2992557.

Page, Roderic D. M., and Michael A. Charleston. 1997. "From Gene to Organismal Phylogeny: Reconciled Trees and the Gene Tree/Species Tree Problem." Molecular Phylogenetics and Evolution 7 (2): 231-240. doi:10.1006/mpev.1996.0390.

Pease, James B., David C. Haak, Matthew W. Hahn, and Leonie C. Moyle. 2016. "Phylogenomics Reveals Three Sources of Adaptive Variation during a Rapid Radiation.” PLoS Biology 14 (2): 124. doi:10.1371/journal.pbio.1002379. 
Pradeu, Thomas. 2012. The Limits of the Self: Immunology and Biological Identity. Translated by Elizabeth Vitanza. New York: Oxford University Press.

Queiroz, K. de, and J. Gauthier. 1992. "Phylogenetic Taxonomy.” Annual Review of Ecology and Systematics 23 (1): 449-480. doi:10.1146/annurev.es.23.110192.002313.

Queiroz, Kevin de. 2007. "Species Concepts and Species Delimitation.” Systematic Biology 56 (6): 879886. doi:10.1080/10635150701701083.

Salipante, Stephen J., and Marshall S. Horwitz. 2006. "Phylogenetic Fate Mapping." Proceedings of the National Academy of Sciences 103 (14): 5448-5453. doi:10.1073/pnas.0601265103.

San Jose, Michael, Camiel Doorenweerd, Luc Leblanc, Norman Barr, Scott Geib, and Daniel Rubinoff. 2018. "Incongruence between Molecules and Morphology: A Seven-Gene Phylogeny of Dacini Fruit Flies Paves the Way for Reclassification (Diptera: Tephritidae).” Molecular Phylogenetics and Evolution 121:139-149. doi:10.1016/j.ympev.2017.12.001.

Slater, Matthew H. 2015. "Natural Kindness.” The British Journal for the Philosophy of Science 66 (2): 375-411. doi:10.1093/bjps/axt033.

Sterner, Beckett. Forthcoming. "Evolutionary Species in Light of Population Genomics.” Philosophy of Science.

Sudianto, Edi, Chung-Shien Wu, Ching-Ping Lin, and Shu-Miaw Chaw. 2016. "Revisiting the Plastid Phylogenomics of Pinaceae with Two Complete Plastomes of Pseudolarix and Tsuga.” Genome Biology and Evolution 8 (6): 1804-1811. doi:10.1093/gbe/evw106.

Tajima, Fumio. 1983. "Evolutionary Relationship of DNA Sequences in Finite Populations." Genetics 105 (2): 437-460. doi:10.1007/bf02103140.

Takahata, N. 1989. "Gene Genealogy in Three Related Populations: Consistency Probability between Gene and Population Trees.” Genetics 122 (4): 957-966. doi:10.1016/0040-5809(90)90018-q.

Takahata, Naoyuki, and Masatoshi Nei. 1985. "Gene Genealogy and Variance of Interpopulational Nucleotide Differences.” Genetics 110 (2): 325-344. doi:10.2142/biophys.28.16.

Velasco, Joel D. 2010. "Species, Genes, and the Tree of Life." British Journal of the Philosophy of Science 61 (3): 599-619. doi:10.1093/bjps/axp051.

Vollmer, Steven V., and Stephen R. Palumbi. 2002. "Hybridization and the Evolution of Reef Coral Diversity.” Science 296 (5575): 2023-2025. doi:10.1126/science.1069524.

Wilkins, John S. 2009. Species: A History of the Idea. Berkeley: Univ. of California Press.

Wilkinson, David M. 1997. "The Role of Seed Dispersal in the Evolution of Mycorrhizae." Oikos 78 (2): 394-396. doi:10.2307/3546308.

Willyard, Ann, Richard Cronn, and Aaron Liston. 2009. "Reticulate Evolution and Incomplete Lineage Sorting among the Ponderosa Pines." Molecular Phylogenetics and Evolution 52 (2): 498-511. doi:10.1016/j.ympev.2009.02.011.

Wray, Gregory A., Hopi E. Hoekstra, Douglas J. Futuyma, Richard E. Lenski, Trudy F. C. Mackay, Dolph Schluter, and Joan E. Strassmann. 2014. "Does Evolutionary Theory Need a Rethink? No, All Is Well.” Nature 514 (7521): 161-164. doi:10.1038/514161a.

(C) 2019 Author(s) This is an open-access article distributed under the terms of the Creative Commons Attribution 4.0 International license, which permits anyone to download, copy, distribute, display, or adapt the text without asking for permission, provided that the creator(s) are given full credit.

ISSN 2475-3025

๑ OPEN ACCESS - PTPBIO.ORG 